\title{
De huisarts: van eenpitter naar netwerkregisseur voor sociaal-medische zorg en leefstijlondersteuning
}

\author{
Maria Jansen
}

Published online: 11 February 2019

(C) The Author(s) 2019

De toekomstige huisartsenzorg staat voor grote uitdagingen. Was de huisarts in het verleden de vertrouwensdokter van zijn patiënt als die zich met klachten meldde, in de komende tien jaar zal de huisarts veel meer teamspeler zijn. Naast de huisarts staan de praktijkondersteuner - in veel huisartsenpraktijken al de normaalste zaak -, de fysiotherapeut, de tandarts, de wijkverpleegkundige, de Wmo-consulent, de arbeidsconsulent, de maatschappelijk werker, de specialist uit het nabijgelegen ziekenhuis die wekelijks spreekuur houdt of expertise inbrengt, de diëtist, de leefstijlcoach, de mantelzorgondersteuner en de welzijnswerker. Zorggroepen ondersteunen deze buurtgerichte netwerken bij het regionale netwerkmanagement.

\section{De huisarts als poortwachter}

In het Nederlandse zorgstelsel beslist de huisarts over verwijzing naar de specialistische zorg, voor nadere diagnostiek of behandeling. Daar is de afgelopen jaren min of meer vanzelf de doorverwijzing naar de praktijkondersteuner aan toegevoegd. De praktijkondersteuner ontlast de huisarts door laagcomplexe medische controle van de huisarts over te nemen en leefstijlondersteuning aan te bieden. Voor die leefstijlondersteuning maakt de praktijkondersteuner gebruik van sport-, beweeg-, en sociale voorzieningen in de buurt. De huisarts fungeert dus als schakelpunt tussen specialist richting tweede lijn en praktijkondersteuner richting basiszorg in de buurt. De huisarts van de toekomst zal als schakelpunt optreden voor geïntegreerde sociaal-medische zorg en (groepsgerichte) leefstijlcoaching in de buurt. Immers, de over-

\section{Jansen $(\bowtie)$}

Academische werkplaats Publieke Gezondheid, GGD Zuid Limburg, Universiteit Maastricht, Maastricht, Nederland Maria.jansen@ggdzl.nl heveling van taken van het rijk naar de gemeenten op het gebied van jeugdzorg, maatschappelijke ondersteuning, arbeidsparticipatie en de langdurige zorg voor zieken en ouderen dwingt tot een heroriëntatie op de huisartsenzorg.

Die huisartsenzorg is tot op heden vooral medische zorg. Huisartsen zijn vooral medisch geschoold. Ziekten zijn het uitgangspunt in de opleiding tot geneeskundige. Maar positieve gezondheid - een breed omarmd begrip - kijkt veel breder dan alleen de medische conditie. Positieve gezondheid wordt gezien als een dynamisch evenwicht tussen de leefomgeving waarin mensen verkeren en hun fysieke, mentale en sociale vermogens waarmee zij zichzelf (of met behulp van anderen) kunnen verweren tegen verstoringen van dit evenwicht. In samenhang kijken naar de medische, sociale, mentale en fysieke conditie, zoals al jaren bepleit wordt [1], vraagt een andere huisartsenzorg. Daarvoor zijn allianties tussen de meer op het individu gerichte gezondheidszorg, de sociale zorg en de publieke gezondheidszorg noodzakelijk. Maar allianties tussen eerste- en tweedelijnszorgpartijen en gemeenten, die verantwoordelijk zijn voor sociale zorg en publieke gezondheidszorg, zijn niet vanzelfsprekend.

\section{Makkelijker gezegd dan gedaan}

Ondanks de vele goede initiatieven om te komen tot geïntegreerde zorg blijkt het lastig om gemeenten en huisartsen tot elkaar te brengen. Partijen onderschrijven de meerwaarde van samenwerken. Zo leggen gemeenten het accent op de thuisomgeving en sociale contacten. Huisartsen letten op de lichamelijke en geestelijke conditie van ouderen. Zo komt de oudere als compleet mens in beeld. Onderzoek uit 2016 laat echter zien dat er grote terughoudendheid bestaat als het gaat om samenwerking. Uit interviews in zes huis- 
artsenpraktijken inclusief hun patiënten in Parkstad, en wethouders en beleidsmedewerkers van de betrokken gemeenten blijkt dat partijen erg argwanend zijn [2]. Huisartsenpraktijken ervaren de gemeenten als star en bureaucratisch, terwijl huisartsen zelf de voorkeur geven aan een pragmatische, flexibele en concrete aanpak. Zij zien ook grote risico's bij het delen van patiëntgegevens, denk aan controle op uitkeringen. In de gedachtegang van veel ambtenaren zouden huisartsen meer tijd vrij moeten maken voor overleg. Overlegtijd krijgen huisartsen niet betaald. En de stroperigheid van gemeentelijke besluitvorming vergt veel overlegtijd, wat op gespannen voet staat met de toegenomen werkdruk bij huisartsen. Er bestaan ook wederzijds misvattingen over elkaars verantwoordelijkheden, werkwijzen en belangen. Patiënten zeggen samenwerking toe te juichen. De huisarts kent de patiënt en zijn situatie van a tot $\mathrm{z}$ en zou de aangewezen persoon zijn om bijvoorbeeld Wmo-consulenten te adviseren over het verstrekken van voorzieningen. Patiënten vertrouwen hierin bovendien op het oordeel van de huisarts. Kortom, de patiënt ligt niet dwars bij de rol van de huisarts als netwerkregisseur.

\section{De huisarts als teamspeler}

Een generalistische, persoonsgerichte benadering van de patiënt en continuïteit van zorg kenmerken de Nederlandse huisartsenzorg. Dat moet ook zo blijven en waar mogelijk versterkt worden, want het zijn juist deze kenmerken die patiënten zo waarderen in hun huisarts [3]. Maar de huisarts van heden en toekomst is geen eenpitter, geen zelfstandig ondernemer, maar een teamspeler. Huisartsenpraktijken maken plaats voor multidisciplinaire gezondheidspraktijken, waar gezondheid in plaats van ziekte het uitgangspunt vormt. Ondernemerschap wordt niet gedreven door financiële prikkels. Incentives van zorgverzekeraars moeten worden heroverwogen. Waar de huisarts het inkomen kan beïnvloeden door extra consulten (circa 9 euro per consult) te voeren en dus minder tijd per patiënt te besteden, dient veel meer geëxperimenteerd te worden met populatiebekostiging.
Om te komen tot sterkere multidisciplinaire gezondheidspraktijken is een efficiëntere organisatie van de huisartsenzorg nodig. Zorggroepen kunnen hierin ondersteuning bieden. Dat kunnen ze ook bij het verhogen van het regionale netwerkmanagement, dat hoeven huisartsen niet allemaal zelf te doen. Zorgverzekeraars zullen in 2019 van start gaan met de financiering van dit netwerkmanagement in de regio. Financiële ontschotting van sociale wijkteams en huisartsenzorg kan sterk bijdragen aan het realiseren van multidisciplinaire gezondheidspraktijken. De huisarts fungeert daarin als schakel in de doorverwijzing naar sociale zorg, leefstijlbegeleiding, medische en specialistische zorg. Kortom, de huisarts als netwerkregisseur.

In deze Spectrum-bijdragen komen de verschillende visies op de toekomstige rol van de huisarts aan de orde, in het bijzonder gericht op preventie. Daarnaast wordt in twee bijdragen uitgebreider stilgestaan bij een aantal meer operationele aspecten die van belang zijn om dit complexe veld toekomstsensitief te maken.

Open Access This article is distributed under the terms of the Creative Commons Attribution 4.0 International License (http://creativecommons.org/licenses/by/4.0/), which permits unrestricted use, distribution, and reproduction in any medium, provided you give appropriate credit to the original author(s) and the source, provide a link to the Creative Commons license, and indicate if changes were made.

\section{Literatuur}

1. Mackenbach J.Ziekten in Nederland. Amsterdam: Elsevier; 2010.

2. Schelleman-Offermans K, Tietschert M, Derickx M, et al. Wijkgericht werken en integrale zorg. De kijk van eerstelijnszorgprofessionals, gemeenten, zorgverzekeraars en patiënten op het integreren van gemeentelijke basiszorg en eerstelijnszorg. Maastricht: Maastricht University; 2015.

3. LHV, NHG. Modernisering naar menselijke maat. Huisartsenzorg in 2022. Utrecht: NHG; 2012. http://www. tkv2022.nl/wp-content/uploads/2012/11/LHV001-37Toekomstvisie-Totaal-Binnenwerk_021112_WWW.pdf. 